Revista de Ensino em Artes, Moda e Design

Dossiê 6

A modelagem integrada ao projeto de Moda no âmbito do ensio

\title{
A NARRATIVA VISUAL NO ENSINO DA FOTOGRAFIA: UMA REVISÃO SISTEMÁTICA DE LITERATURA
}

\section{The visual narrative in photography education: a systematic literature review}

\section{La narrativa visual em la enseñanza de la fotografía: una revisión de literatura sistemática}

\author{
Ana Leticia Oliveira do Amaral ${ }^{1}$ \\ Berenice Santos Gonçalves ${ }^{2}$ \\ Edgar Bisset Alvarez ${ }^{3}$
}

\footnotetext{
${ }^{1}$ Bacharel em Desenho Industrial - Habilitação em Programação Visual pela UFSM, especialista em Fotografia pela Universidade de Araraquara e mestre em Design pela Universidade Federal de Santa Catarina (UFSC). Doutoranda na mesma instituição, na linha de Mídia e Tecnologia. E-mail: amaral.analeticia@gmail.com | http://lattes.cnpq.br/5281378566557527 | ORCID 0000-0002-5270-9105.

2 Doutora em Engenharia de Produção pela UFSC, mestre em Artes Visuais pela UFRGS e graduada em Artes Visuais - Bacharelado e Licenciatura pela UFRGS. Professora adjunta na Universidade Federal de Santa Catarina. E-mail: berenice@cce.ufsc.br | http://lattes.cnpq.br/8382731805850046 | ORCID 0000-0002-0740-4281.

${ }^{3}$ Doutor em Ciência da Informação pelo Programa de Pós-Graduação em Ciência da Informação da UNESP, com período sanduíche na Universidad de Murcia/Espanha. Mestre em Biblioteconomia e Ciência da Informação - Universidade da Havana e graduado em Informação Cientifico-Técnica e Biblioteconomia - Universidade da Havana. Professor adjunto na Universidade Federal de Santa Catarina. E-mail: edgar.bisset@ufsc.br | http://lattes.cnpq.br/6259487897392078 | ORCID 0000-0002-5388-5944.
} 


\title{
Resumo
}

A produção de imagens faz parte da evolução da humanidade, bem como está intimamente ligada ao ato de contar histórias. Imagens, em especial as fotográficas, configuram uma poderosa forma de comunicação, visto que mensagens visuais estimulam respostas emocionais e intelectuais, ou seja, elas permitem o sentir e o refletir sobre um determinado assunto. Nessa perspectiva, compreender a relação entre narrativa e fotografia digital é fundamental para potencializar a linguagem visual e imagética, principalmente na formação de profissionais, como designers, que utilizam a fotografia como um recurso constante. Diante disso, este estudo se propôs a identificar pesquisas atuais que abordem a narrativa nos processos de leitura e escrita de imagens fotográficas. Para tanto, adotou-se como método uma revisão sistemática de literatura. A partir dos resultados alcançados nesse processo, é possivel afirmar que os estudos se concentram em três eixos principais: quanto à narrativa criada por coleção, ou seja, narrativa produzida por uma sequência de imagens; quanto à narrativa composta em uma única imagem fixa; e quanto aos métodos e inovações na representação fotográfica. Ao final, fica evidente que o reduzido número de publicações envolvendo estratégias que fomentem o desenvolvimento das habilidades de leitura e de escrita de imagens fotográficas associadas aos estudos narratológicos indicam uma necessidade de ampliação de pesquisas com essa temática.

\section{Palavras-chave: Narrativa; Ensino da fotografia; Revisão Sistemática de Literatura.}

\begin{abstract}
The production of images is part of the evolution of humanity, as well as, it is closely linked to the act of telling stories. Images, especially photographic ones, configure a powerful form of communication, since visual messages stimulate emotional and intellectual responses, that is, they allow feeling and reflecting on a certain subject. In this sense, understanding the relationship between narrative and digital photography is fundamental to enhance the visual and imagery language, especially in the education of professionals, such as designers, who use photography as a constant resource. Therefore, this study aimed to identify current research that addresses issues about the narrative in the processes of reading and writing photographic images. For that, a systematic literature review was adopted as a method. From the results achieved in this process, it is possible to state that the studies focus on three main axes: as for the narrative created by collection, that is, the narrative produced by a sequence of images; as for the narrative composed in a single still image; and as to methods and innovations in photographic representation. In the end, it is evident that the small number of publications involving strategies that foster the development of reading and writing skills of photographic images associated with narratological studies indicate a need to expand research on this theme.
\end{abstract}

Keywords: Narrative; Photography education; Systematic Literature Review. 


\section{Resumen}

La producción de imágenes es parte de la evolución de la humanidad y, además, está estrechamente vinculada al acto de contar historias. Las imágenes, especialmente las fotográficas, configuran una forma poderosa de comunicación, ya que los mensajes visuales estimulan las respuestas emocionales e intelectuales, es decir, permiten sentir y reflexionar sobre un determinado tema. En este sentido, comprender la relación entre la fotografía narrativa y la digital es esencial para mejorar el lenguaje visual y de imágenes, especialmente en la formación de profesionales, como diseñadores, que utilizan la fotografía como un recurso constante. Por lo tanto, este estudio tuvo como objetivo identificar investigaciones actuales que aborden problemas sobre la narrativa en los procesos de lectura y escritura de imágenes fotográficas. Para eso, se adoptó una revisión sistemática de la literatura como método. A partir de los resultados obtenidos en este proceso, es posible afirmar que los estudios se centran en tres ejes principales: en cuanto a la narrativa creada por la colección, es decir, la narrativa producida por una secuencia de imágenes; en cuanto a la narrativa compuesta en una sola imagen fija; y en cuanto a métodos e innovaciones en representación fotográfica. Al final, es evidente que el pequeño número de publicaciones que involucran estrategias que fomentan el desarrollo de las habilidades de lectura y escritura de imágenes fotográficas asociadas con estudios narratológicos indican la necesidad de ampliar la investigación sobre este tema.

Palabras-clave: Narrativa; Enseñanza de la fotografía; Revisión sistemática de literatura.

\section{INTRODUÇÃO}

Produzir imagens faz parte da evolução da humanidade. Pode-se dizer que hoje a imagem fotográfica integra o cotidiano do homem contemporâneo, seja informando, formando ou impulsionando à reflexão (SOBRAL, 2011). Na sociedade atual, a imagem fotográfica possui uma presença ubíqua, onde diversos aparatos capturam e compartilham milhões de imagens a todo o momento em todo o mundo (HAND, 2012; SANTAELLA, 2014; MANOVICH, 2017). As funcionalidades dos equipamentos tecnológicos se unem para potencializar a mobilidade e a interatividade dos conteúdos, mudando as relações sociais, tecnológicas, econômicas e industriais. Entretanto, apesar da imagem fotográfica ter sido trivializada na atualidade (SANTAELLA, 2014), ela tem uma utilização fundamental e extensiva no estudo de diversas áreas do conhecimento (RUBINSTEIN, 2009), possui uma estreita relação com as atividades do Design e constitui-se primordial à produção cultural contemporânea.

A compreensão da relação entre narrativa e fotografia digital é fundamental para potencializar a linguagem visual e imagética, principalmente na formação de profissionais, como designers, que utilizam a fotografia como um recurso constante. Como afirma Arlindo Machado (2000), a fotografia é a base ideológica, conceitual e 
tecnológica de todas as mídias contemporâneas e, dessa forma, ao compreendê-la e defini-la, é possível entender as estratégias semióticas, os modelos de construção e percepção e as estruturas de sustentação de toda a produção contemporânea de signos visuais e auditivos.

Dessa maneira, diante da complexidade do sistema midiático contemporâneo, em que as transformações tecnológicas são regidas por uma dinâmica acelerada, "a sociedade se encontra imersa em conteúdos imagéticos de múltiplas naturezas e está sempre à procura de experimentar novas práticas, o que exige das mídias uma constante busca de novas competências." (FALANDES; ANGELUCl, 2019, p. 211).

Assim, partiu-se do pressuposto de que a narrativa visual no contexto do ensino da fotografia, atrelada ao digital, pode atuar na produção de conhecimento, ampliando as possibilidades das produções fotográficas, estimulando a participação do aluno como sujeito ativo desse processo e promovendo o desenvolvimento de habilidades, como o trabalho colaborativo e o pensamento crítico.

Nesse sentido, este estudo se propôs a identificar pesquisas atuais que abordem a narrativa nos processos de leitura e escrita de imagens fotográficas. Para tanto, realizou-se uma Revisão Sistemática de Literatura (RSL). Este método adota um processo replicável, científico e transparente e se dá por meio de buscas exaustivas em estudos publicados em base de dados, assim como fornece um registro das decisões, procedimentos e conclusões dos pesquisadores (WEBSTER; WATSON, 2002; TRANFIELD; DENYER; SMART, 2003; LEVY; ELLIS, 2006).

\section{ENSINO DA FOTOGRAFIA}

A fotografia, desde a sua invenção, teve estreita relação com as mudanças sociais, com as evoluções tecnológicas e com as relações informacionais da humanidade. Guedes (2016) destaca que, no decorrer da sua história, a fotografia alterou profundamente as coordenadas de espaço e tempo na comunicação humana. Nesse sentido, para Abrahmov e Ronen (2008), o objetivo do ensino de fotografia é desenvolver habilidades tanto de "leitura" quanto de "escrita" de imagens. Para os autores, explorar o significado de uma fotografia deve ser mais parecido com a leitura de uma frase complexa do que com a leitura de uma única palavra. Já para Rivera (2012), aprender a tirar fotos é selecionar um olhar entre muitos olhares possíveis, dessa maneira, adquirindo os critérios necessários para selecionar um ponto de vista no espaço e no tempo. Assim, ao se tornarem criadores e leitores de imagens, os estudantes aprendem habilidades de comunicação e resolução de problemas, tornando-se mais aptos a navegar na cultura cada vez mais visual (RIVERA, 2012).

Para Nieberding (2011), antes da popularização da fotografia digital, os alunos memorizavam configurações de f/stops e velocidades do obturador, aprendiam as regras de composição, de processamento de filmes que dominavam o mercado e de amplificadores usados para fazer impressões tecnicamente excelentes. O objetivo do ensino nessa área estava ligado ao domínio da arte, da técnica e da tecnologia de fazer fotografias. Atualmente, a educação fotográfica parece possuir como principal objetivo educar a respeito dos usos do meio, fornecendo uma estrutura crítica para 
a interpretação de imagens, promovendo a alfabetização visual e o letramento imagético ${ }^{1}$.

\section{NARRATIVA NO ENSINO}

De acordo com Brunner (1991), a narrativa pode ser descrita como um modo de pensar, uma forma da humanidade organizar as suas experiências e ainda como um recurso no processo da educação. Nesse sentido, Teixeira (2019) menciona que a narrativa trata de representar histórias em uma estrutura epistemológica crítica, a qual busca organizar um padrão explicativo para que os eventos façam sentido. Assim, a narrativa é baseada em uma relação de causa e efeito, afim de estruturar os eventos dentro da história.

Explorar a narrativa para acessar a experiência dos alunos no processo de ensino-aprendizagem é um meio para se compreender como eles representam o conhecimento a partir da relação com o contexto de formação no qual estão inseridos. Bem como, esse movimento cria elementos para que os alunos possam refletir sobre suas vivências de aprendizagem (PALÁCIO; CIANNELLA; STRUCHINER, 2017).

Apesar da fotografia ainda ser mantida à margem das investigações narratológicas (BAETENS, 2009), ela está intimamente ligada ao ato de contar histórias. Imagens, em especial as fotográficas, configuram uma poderosa forma de comunicação, visto que mensagens visuais estimulam respostas emocionais e intelectuais, ou seja, elas permitem o sentir e o refletir sobre um determinado assunto (PETTERSON, 2019). Dessa maneira, infere-se que a narrativa visual, atrelada ao digital, pode atuar como uma possibilidade na produção de conhecimento, ampliando as possibilidades das produções fotográficas, estimulando a participação do aluno como sujeito ativo desse processo e promovendo o desenvolvimento de habilidades, como o trabalho colaborativo e o pensamento crítico.

\section{PROCEDIMENTOS METODOLÓGICOS}

Para o presente estudo, foi realizada uma RSL de caráter exploratório, baseada no método proposto por Sampaio e Mancini (2007). Este tipo de investigação científica fornece evidências relacionadas a uma estratégia de intervenção específica por meio de uma aplicação de método de pesquisa explícito e sistematizado, de apreciação crítica e síntese da informação selecionada. Dessa maneira, deve ser executada de modo confiável, sistemático e compreensível (SAMPAIO; MANCINI, 2007; WEBSTER; WATSON, 2002; LEVY; ELLIS, 2006). O método de Sampaio e Mancini (2007) é dividido em cinco etapas, como pode ser visto na figura 1, a saber: (I) definir a pergunta, (II) buscar a evidência, (III) revisar e selecionar os estudos, (IV) analisar a qualidade metodológica dos estudos e (V) apresentar os resultados.

\footnotetext{
${ }^{1}$ De acordo com Rodrigues (2014), entende-se alfabetização como o aprendizado das bases de uma linguagem e letramento como o aprendizado das práticas sociais simbólicas, as quais são utilizadas a partir do uso fluente da língua.
} 
Figura 1 - Etapas da revisão sistemática

\begin{tabular}{|c|c|c|c|c|}
\hline $1 \begin{array}{l}\text { DEFINIRA } \\
\text { PERGUNTA }\end{array}$ & & 3 & & $\begin{array}{l}\text { TAR } \\
\text { TADOS }\end{array}$ \\
\hline $\begin{array}{l}\text { Definir a pergunta } \\
\text { científica } \\
\text { especificando a } \\
\text { população e a } \\
\text { intervenção em } \\
\text { interesse }\end{array}$ & $\begin{array}{l}\text { Identificar as bases } \\
\text { de dados que serão } \\
\text { consultadas, definir } \\
\text { as palavras-chave e } \\
\text { estratégias de busca }\end{array}$ & $\begin{array}{l}\text { Definição e aplicação } \\
\text { dos critérios de } \\
\text { inclusão e exclusão e } \\
\text { estratégias para a } \\
\text { seleção das } \\
\text { referências }\end{array}$ & $\begin{array}{l}\text { Análise crítica, } \\
\text { avaliação e síntese } \\
\text { dos estudos } \\
\text { selecionados }\end{array}$ & $\begin{array}{l}\text { Apresentação } \\
\text { dos resultadose } \\
\text { conclusões }\end{array}$ \\
\hline
\end{tabular}

Fonte: Elaborado pela autora com base em Sampaio e Mancini (2007)

Definida a questão de pesquisa - identificar pesquisas atuais que abordem a narrativa nos processos de leitura e escrita de imagens fotográficas - com base no método proposto, a estratégia de busca foi desenvolvida a partir da definição de dois eixos relevantes ao estudo: ensino da fotografia e narrativa. As palavras-chave utilizadas na construção da string ${ }^{2}$ final de busca e os termos sinônimos são apresentadas no quadro 1, a seguir.

Quadro 1 - Relação das palavras-chave

\begin{tabular}{|c|c|}
\hline Ensino da fotografia & Narrativa \\
\hline teaching photography & narrative \\
\hline photography education & visual narrative \\
\hline photography instruction & imagetic narrative \\
\hline photography & \\
\hline
\end{tabular}

Fonte: Elaborado pela autora (2020)

No desenvolvimento da string houve certo enfrentamento na escolha dos termos relacionados que melhor se adequavam, visto que a expressão "ensino da fotografia" por vezes se confundia com "fotografia para o ensino". Contudo, foram testadas diversas combinações de termos relacionados às palavras-chave até se chegar ao arranjo que gerou um resultado mais satisfatório ao escopo desta pesquisa.

Dessa forma, para ligar os termos sinônimos de cada eixo, foi utilizado o operador booleano "OR". Já para ligar os dois eixos ensino da fotografia e narrativa o operador "AND" foi empregado. Além disso, optou-se por utilizar o asterisco no radical da palavra "photograph*" para alcançar mais variações nominais. Assim, a string final de busca foi definida como: (photograph* OR "photography education" OR "teaching photography" OR "photography instruction") AND (narrative OR "visual narrative" OR "imagetic narrative").

A busca das evidências se deu em três bases de dados internacionais, sendo elas Scopus, Web of Science e ProQuest. As bases foram escolhidas devido à recorrência na área de Ciências Sociais Aplicadas e por serem os maiores bancos de dados multidisciplinares. A busca ocorreu em dois dias consecutivos (14 e 15 de janeiro de 2020), com a string construída, identificando-se os seguintes resultados:

${ }^{2}$ Conjunto de palavras e termos referentes ao tema da pesquisa conectados por operadores lógicos AND e OR (Fabbri; Octaviano; Hernandes, 2017). 
Quadro 2 - Resultados numéricos da busca

\begin{tabular}{|c|c|c|c|c|}
\hline String & Scopus & Wos & ProQuest & Total \\
\hline $\begin{array}{c}\text { (photograph* OR "photography edu- } \\
\text { cation" OR "teaching photography" OR }\end{array}$ & & & & \\
$\begin{array}{c}\text { "photography instruction") AND (narra- } \\
\text { tive OR "visual narrative" OR "imagetic } \\
\text { narrative") }\end{array}$ & 1163 & 1112 & 65 & 2340 \\
\hline
\end{tabular}

Fonte: Elaborado pela autora (2020)

Foram buscados artigos de periódicos publicados ou aceitos para publicação, bem como artigos de anais de congressos publicados nos últimos 10 anos (20092019), sem especificação de área. Ressalta-se que todas as bases foram acessadas por meio do sistema CAPES. Quanto ao idioma, foram selecionadas apenas referências escritas em português, espanhol e inglês. Em relação ao acesso, foram mantidos apenas os artigos acessíveis gratuitamente por meio de: (1) Portal de Periódicos da CAPES na instituição Universidade Federal de Santa Catarina - UFSC; (2) Google Acadêmico; (3) Portal das editoras e (4) através do sistema COMUT na instituição envolvida. Para o processo de seleção, as referências encontradas nas bases de dados foram exportadas - com todas as suas informações - nos formatos .BibTEX e .RIS para, em seguida, serem importadas no gerenciador de referências Rayyan, que organiza os documentos em uma lista por data, título do artigo e autor. O software ainda permite classificar as referências em três instâncias: incluído, talvez e excluído. Além disso, esta ferramenta permite a verificação da existência e exclusão de referências duplicadas entre as buscas.

Pesquisas que abordavam no seu escopo questões sobre a inserção da fotografia no ensino proporcionado por escolas e pesquisas que tratavam a fotografia como ferramenta auxiliar nos processos de documentação de procedimentos específicos, foram excluídas por não se enquadrarem ao escopo desse estudo. Assim, foi aplicada a primeira filtragem, constituída pela leitura do título e palavras-chave dos artigos encontrados. Após a exclusão dos documentos que não tinham relação com o tema, foi realizada a segunda filtragem, ou seja, a leitura do título, resumo e palavras-chave dos artigos. Para a terceira etapa, que foi constituída pela leitura dos documentos na íntegra, foram buscados os PDFs das referências selecionadas. As referências para as quais não foi possível a obtenção dos arquivos PDF pelos meios descritos anteriormente, foram excluídas do portfólio final. $O$ critério de seleção dos trabalhos foi o nível de contribuição para responder à pergunta de pesquisa proposta.

Dessa forma, obteve-se um portfólio com 12 artigos, contudo, seis referências foram excluídas, uma que não foi possível encontrar o arquivo PDF e as demais não se adequavam aos critérios estabelecidos nesta pesquisa. A figura 2 sintetiza o processo de filtragem das referências. 
Figura 2 - Processo de seleção dos documentos

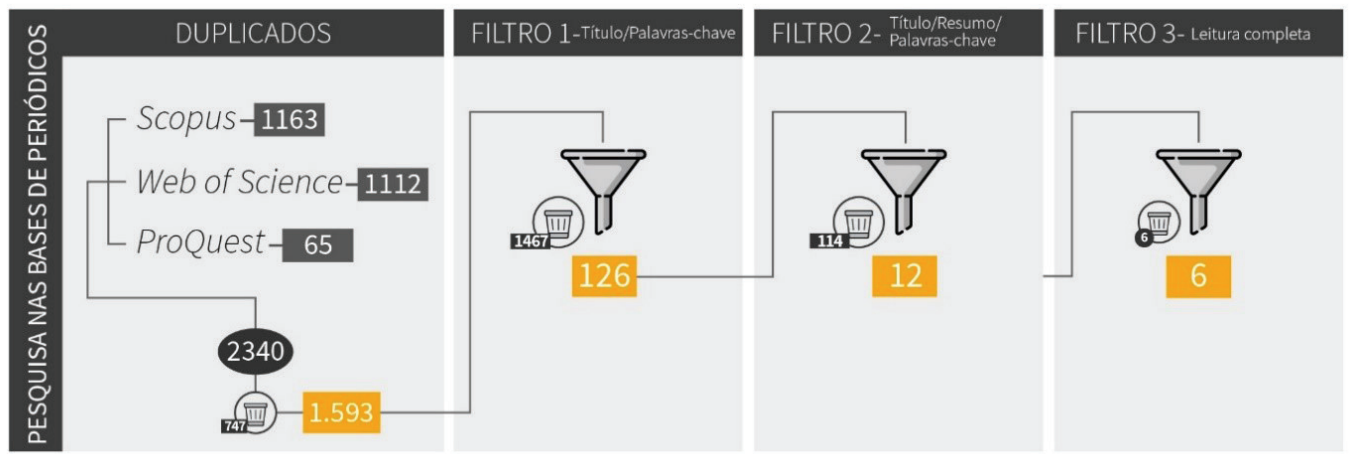

Fonte: Elaborado pela autora (2020)

\section{RESULTADOS E DISCUSSÕES}

O portfólio final de referências apresenta um total de seis publicações, sendo todas provenientes da base de dados Scopus. $O$ quadro 3, a seguir, apresenta o ano de publicação, nome dos autores, título das referências, o objetivo da pesquisa e 0 periódico de publicação.

Quadro 3 - Extração dos dados gerais das publicações

\begin{tabular}{|c|c|c|c|c|}
\hline Ano & Autor & Título & Objetivo & Periódico \\
\hline 2019 & $\begin{array}{l}\text { Yasmine Ei- } \\
\text { d-Sabbagh }\end{array}$ & $\begin{array}{c}\text { Extending } \\
\text { Photography: } \\
\text { the Meta-Me- } \\
\text { dial/Conversa- } \\
\text { tional Layers of } \\
\text { Dematerialized } \\
\text { Photographs }\end{array}$ & $\begin{array}{l}\text { Analisar uma coleção de } \\
\text { fotografias digitais, por meio } \\
\text { de uma prática de pesquisa } \\
\text { baseada em artes, na qual as } \\
\text { fotografias são tratadas como } \\
\text { substâncias de múltiplas ca- } \\
\text { madas, compostas de objeto } \\
\text { físico com diferentes cama- } \\
\text { das meta-mediais, a fim de } \\
\text { considerar os desafios éticos, } \\
\text { teóricos e práticos de cap- } \\
\text { tar emoções, subjetividades, } \\
\text { experiências e políticas que } \\
\text { excedem a imagem material } \\
\text { da própria coleção }\end{array}$ & $\begin{array}{l}\text { Photography } \\
\text { and Culture }\end{array}$ \\
\hline
\end{tabular}




\begin{tabular}{|c|c|c|c|c|}
\hline 2018 & $\begin{array}{c}\text { Andrea C. } \\
\text { Klimt }\end{array}$ & $\begin{array}{l}\text { New ways of } \\
\text { seeing: enhan- } \\
\text { cing student } \\
\text { learning throu- } \\
\text { gh commu- } \\
\text { nity-based } \\
\text { collaborative } \\
\text { photography }\end{array}$ & $\begin{array}{l}\text { Refletir sobre as abor- } \\
\text { dagens e inovações funda- } \\
\text { mentais para a exploração da } \\
\text { relação entre representações } \\
\text { fotográficas e realidade }\end{array}$ & Visual Studies \\
\hline 2017 & $\begin{array}{l}\text { Joaquín B. } \\
\text { López-del- } \\
\text {-Ramo }\end{array}$ & $\begin{array}{c}\text { Formatos } \\
\text { novedosos } \\
\text { del fotoperio- } \\
\text { dismo digital. } \\
\text { Propuesta ana- } \\
\text { lítica basada } \\
\text { en indicadores } \\
\text { estructurales, } \\
\text { formales y fun- } \\
\text { cionales }\end{array}$ & $\begin{array}{l}\text { Examinar métodos fo- } \\
\text { tojornalísticos emergentes, } \\
\text { com ênfase na identificação, } \\
\text { classificação e descrição } \\
\text { sistemática de seus atributos } \\
\text { básicos e lógica subjacente, a } \\
\text { fim de ter um conhecimento } \\
\text { atualizado desses métodos e } \\
\text { influenciar a possível melho- } \\
\text { ria de seus padrões de quali- } \\
\text { dade }\end{array}$ & $\begin{array}{r}\text { Investigación } \\
\text { bibliotecoló- } \\
\text { gica }\end{array}$ \\
\hline 2010 & Jan Baetens & $\begin{array}{l}\text { Is a photo- } \\
\text { graph worth } \\
\text { a thousand } \\
\quad \text { films? }\end{array}$ & $\begin{array}{l}\text { Examinar o poder nar- } \\
\text { rativo de um meio que se } \\
\text { considera incapaz de realizar } \\
\text { tarefas narrativas: fotografia }\end{array}$ & Visual Studies \\
\hline 2009 & $\begin{array}{l}\text { Michael } \\
\text { Schwalbe }\end{array}$ & $\begin{array}{c}\text { Framing the } \\
\text { Self }\end{array}$ & $\begin{array}{l}\text { Refletir sobre como o } \\
\text { enquadramento da imagem } \\
\text { constrói a história e dá senti- } \\
\text { do a uma fotografia }\end{array}$ & $\begin{array}{l}\text { Symbolic } \\
\text { Interaction }\end{array}$ \\
\hline 2007 & $\begin{array}{c}\text { Fernanda } \\
\text { Jansen Mira } \\
\text { Catanho }\end{array}$ & $\begin{array}{c}\text { A edição foto- } \\
\text { gráfica como } \\
\text { construção de } \\
\text { uma narrativa } \\
\text { visual }\end{array}$ & $\begin{array}{l}\text { Aferir se o receptor da } \\
\text { mensagem fotográfica iden- } \\
\text { tificaria, de uma edição para } \\
\text { outra, as diferentes visões } \\
\text { sobre um mesmo assunto }\end{array}$ & $\begin{array}{l}\text { Discursos } \\
\text { Fotográficos }\end{array}$ \\
\hline
\end{tabular}

Fonte: Elaborado pela autora (2020)

As pesquisas analisadas abordam a narrativa relacionada aos processos de leitura e escrita de imagens fotográficas de maneiras bem distintas. É possível afirmar que os estudos se concentram em três eixos principais: quanto à narrativa criada por coleção, ou seja, narrativa produzida por uma sequência de imagens (EID-SABBAGH, 2019; CATANHO, 2007); quanto à narrativa composta em uma única imagem fixa (SCHWALBE, 2009; BAETENS, 2010) e quanto aos métodos e inovações na representação fotográfica (LÓPEZ-DEL-RAMO, 2017; KLIMT, 2018).

No primeiro eixo, relacionado às coleções de imagens, o estudo proposto por Catanho (2007) trabalha com a premissa de que a edição fotográfica pode ser responsável pela construção de uma narrativa visual e está situado na área do jornalismo. Já o estudo relatado por Eid-Sabbagh (2019) utiliza um método de pesquisa no 
qual as imagens são tratadas como substâncias de múltiplas camadas.

Para Catanho (2007) a imagem em si é um elemento de enunciação discursiva e a união de duas ou mais imagens pode gerar um novo conceito ou sentido diferente do que as imagens isoladas criariam. Assim, no artigo analisado, a autora apresenta a técnica de montagem intelectual na edição de imagens, visto que o papel da edição é produzir significados a partir de unidades imagéticas que já possuem um sentido próprio. Em seu experimento, foi adotado um ensaio fotográfico composto por 26 fotografias, foi ainda solicitado que três especialistas editassem o ensaio e, como resultado, obteve-se três narrativas diferentes. Catanho (2007), por fim, afirma que fica evidente que a mensagem fotográfica pode passar por uma reelaboração criativa e formar discursos enunciativos distintos.

Já para Eid-Sabbagh (2019) uma gravação sonora, na qual uma pessoa fala sobre uma fotografia, expressa uma emoção ou simplesmente personifica o silêncio, é considerada uma versão de uma fotografia, assim como o negativo e uma impressão são duas versões diferentes de uma fotografia. Essas diversas narrativas e camadas ativas que cobrem as camadas de material incorporadas de uma fotografia, são chamadas de camadas meta-mediais. A autora defende que algumas das camadas meta-mediais são conceituais e outras até fictícias, mas todas têm uma função: todas têm como objetivo mediar a relação dos colaboradores e dos espectadores com a coleção, a fim de criar uma coletividade que transcenda as limitações habituais de tempo, espaço e origem/identidade, e que permite novos e múltiplos modos de envolvimento.

Apesar dos dois artigos tratarem sobre a leitura de imagens, o estudo proposto por Catanho (2007) tem seu maior foco na construção da narrativa, ou seja, na escrita das imagens. Contudo, as técnicas utilizadas nas duas pesquisas apresentam amplo potencial de utilização no ensino da fotografia ao fornecerem uma estrutura crítica para a interpretação de imagens.

No segundo eixo, quanto à narrativa de uma imagem fixa, a pesquisa relatada por Schwalbe (2009), a partir do relato da construção de um retrato, reflete sobre como o enquadramento da imagem constrói a história e dá sentido a uma fotografia. O autor afirma que sem uma história plausível de enquadramento, mesmo que imaginada, o leitor continua inseguro sobre como reagir quanto à imagem e, talvez, cauteloso em ser manipulado. Visto que o enquadramento fotográfico geralmente se refere ao que foi incluído ou excluído da fotografia, o conteúdo da imagem influencia as histórias que estas evocam e que podem ser contadas sobre elas, bem como o quadro visual escolhido pelo fotógrafo também pode ser influenciado pelo quadro narrativo que o profissional traz, consciente ou inconscientemente, ao processo de criação de imagens (HAGAMAN, 1996; SCHWALBE, 2009).

Contudo, Baetens (2010), de modo mais abrangente, buscou examinar a capacidade narrativa da fotografia. O autor inicia seu estudo apresentando argumentos que desfavorecem o potencial narratológico de uma fotografia para, então, construir seus argumentos a partir da comparação entre a imagem fotográfica fixa e a sua remediação (conceito de Bolter e Grusin, 1999): o filme. Baetens (2010) ainda afirma que apesar do interesse no tempo, na história e na ficção presente na fotografia contemporânea, os preconceitos contra a fotografia orientada por narrativas permane- 
cem poderosos, como se o próprio meio pudesse se tornar apenas uma ferramenta narrativa em um ambiente periférico e de maneira secundária. $O$ autor ainda menciona que a narrativa imagética depende, de modo geral, de como se lê o que a imagem mostra. Assim, a aptidão de uma imagem para contar histórias não é uma função da ação dentro da imagem, mas da maneira como o leitor considera adequado ler essa imagem como uma história. Pode-se dizer que esse primeiro aspecto deve estar situado no nível de representação e o segundo no nível de compreensão.

Por fim, o terceiro eixo, onde ficaram as pesquisas relacionadas aos métodos e inovações na representação fotográfica, López-del-Ramo (2017) buscou examinar métodos fotojornalísticos emergentes, com ênfase na identificação, classificação e descrição sistemática de seus atributos. Como resultado, o autor apresenta um instrumento metodologicamente baseado na análise do conteúdo, que forma um livro de registro para o exame empírico dos novos formatos fotográficos com base em dados objetivos e verificáveis.

Já o estudo desenvolvido por Klimt (2018) é a única referência encontrada voltada ao ensino da fotografia. Consistiu em uma iniciativa de aproximar os acadêmicos de uma disciplina de fotografia e cultura visual da sociedade, por meio de um projeto colaborativo de fotografia baseado na comunidade. O propósito do projeto era documentar uma comunidade especifica, a qual os alunos, em um questionamento prévio, descreveram como "perigosa, suja e feia". A autora afirma que a participação se tornou o meio pelo qual os alunos obtiveram uma compreensão mais profunda dos debates teóricos em sociologia visual e antropologia, transformando suas suposições desinformadas em insights e os permitindo dar uma contribuição significativa.

Ademais, com base nos resultados da RSL, é possível visualizar que os artigos são de origem geográfica dispersa. Cabe destacar que dois (2) são originários dos Estados Unidos e dois (2) da Áustria. Salienta-se ainda que nos países Espanha e Brasil foram encontradas apenas uma publicação para cada. No que tange a evolução das publicações ao longo dos últimos 10 anos, percebe-se uma lacuna de 7 anos entre 2010 e 2017. Além disso, as pesquisas são oriundas de diferentes áreas do conhecimento, visto que dois (2) artigos estão vinculados à sociologia e antropologia, dois (2) ao jornalismo, um (1) às artes e um (1) aos estudos culturais.

Quadro 4 - Localização dos dados das publicações

\begin{tabular}{|c|c|c|c|c|}
\hline Título & Ano & País & Universidade & $\begin{array}{c}\text { Área de } \\
\text { concentra- } \\
\text { ção }\end{array}$ \\
\hline $\begin{array}{c}\text { Extending Photography: the } \\
\text { Meta-Medial/Conversational Layers } \\
\text { of Dematerialized Photographs }\end{array}$ & 2019 & Áustria & $\begin{array}{c}\text { Academy of } \\
\text { Fine Arts }\end{array}$ & Artes \\
\hline $\begin{array}{c}\text { New ways of seeing: enhan- } \\
\text { cing student learning through } \\
\text { community-based collaborative } \\
\text { photography }\end{array}$ & 2018 & EUA & $\begin{array}{c}\text { University of } \\
\text { Massachusetts }\end{array}$ & $\begin{array}{c}\text { Sociologia } \\
\text { e Antropo- } \\
\text { logia }\end{array}$ \\
\hline
\end{tabular}




\begin{tabular}{|c|c|c|c|c|}
\hline $\begin{array}{c}\text { Formatos novedosos del foto- } \\
\text { periodismo digital. Propuesta ana- } \\
\text { lítica basada en indicadores estruc- } \\
\text { turales, formales y funcionales }\end{array}$ & 2017 & Espanha & $\begin{array}{c}\text { Universidad } \\
\text { Rey Juan Car- } \\
\text { los }\end{array}$ & Jornalismo \\
\hline $\begin{array}{r}\text { Is a photograph worth a thou- } \\
\text { sand films? }\end{array}$ & 2010 & Áustria & $\begin{array}{c}\text { University of } \\
\text { Leuven }\end{array}$ & $\begin{array}{c}\text { Estudos } \\
\text { culturais }\end{array}$ \\
\hline Framing the Self & 2009 & EUA & $\begin{array}{c}\text { North Carolina } \\
\text { State Univer- } \\
\text { sity }\end{array}$ & $\begin{array}{c}\text { Sociologia } \\
\text { e Antropo- } \\
\text { logia }\end{array}$ \\
\hline $\begin{array}{c}\text { A edição fotográfica como } \\
\text { construção de uma narrativa visual }\end{array}$ & 2007 & Brasil & $\begin{array}{c}\text { Universidade } \\
\text { Estadual de } \\
\text { Londrina }\end{array}$ & Jornalismo \\
\hline
\end{tabular}

Diante disso, os resultados obtidos são de diversas áreas e concentram seus estudos em diferentes aspectos da narrativa imagética. Ademais, Baetens (2010) menciona em seu estudo que as imagens fotográficas ainda são mantidas à margem da investigação narratológica. Além disso, não foram encontrados estudos que buscam inserir reflexões ou até mesmo técnicas para construção e análise de narrativas no ensino da fotografia para graduações de Design. Dessa maneira, considerando que não foram encontradas pesquisas com tais preocupações, percebe-se a urgência em se propor estratégias que fomentem o desenvolvimento das habilidades de leitura e de escrita de imagens fotográficas associadas aos estudos narratológicos.

\section{CONSIDERAÇÕES FINAIS}

A fotografia possui uma estreita relação com as atividades do Design e constitui-se primordial à produção cultural contemporânea. Nesse sentido, o ensino da fotografia requer o desenvolvimento e aplicação de processos de inovação constantemente para manter a sua relevância frente ao contexto contemporâneo. Partiu-se da premissa que a narrativa visual pode potencializar o ensino da fotografia. Assim, este estudo foi desenvolvido com o objetivo de identificar pesquisas atuais que abordem a narrativa nos processos de leitura e escrita de imagens fotográficas. O levantamento realizado por meio da revisão sistemática de literatura mostrou-se objetivo e claro quanto aos procedimentos e resultados, possibilitando, assim, a replicação do estudo para uma futura atualização. Quanto aos resultados, os artigos coletados apresentaram diferentes linhas de investigação, bem como não são suficientes para a organização de um corpo de conhecimento que possa contribuir com o ensino da fotografia de maneira consistente e eficaz e demonstram a necessidade de se propor estratégias de ensino que fomentem o desenvolvimento das habilidades de leitura e de escrita de imagens fotográficas associadas aos estudos narratológicos.

Uma das limitações encontradas na execução desta revisão sistemática diz respeito a definição das strings de busca, visto que diversas publicações encontra- 
das utilizam como palavras-chave ou indexadores os termos "fotografia", "ensino" e "educação" empregados separadamente. Dessa forma, para abarcar essas publicações, foi necessário utilizar a palavra "photography" de modo isolado, gerando assim um expressivo número de resultados.

Portanto, apesar de inicialmente as buscas terem gerado um número expressivo de retornos, percebeu-se que muitos dos resultados não tinham relação direta com o tema ou não se adequavam ao escopo desta pesquisa. Além disso, frente à utilização extensiva da imagem fotográfica em diversas áreas do conhecimento e da estreita relação com as atividades do Design, o reduzido número de publicações envolvendo preocupações com os processos narrativos relacionados ao ensino da fotografia indicam a necessidade de ampliação de pesquisas com essa temática. ${ }^{3}$

\section{REFERÊNCIAS}

ABRAHMOV, S. L.; RONEN, M. Double blending: online theory with on-campus practice in photography instruction. Innovations in Education and Teaching International, v. 45, n. 1, p. 3-14, 2008.

BAETENS, Jan. Is a photograph worth a thousand films? Visual Studies, v. 24, n. 2, p.143-148, set. 2009.

BRUNER, Jerome. The Narrative Construction of Reality. Critical Inquiry, Chicago, v. 1, n. 18, p. 1-21, 1991.

CATANHO, Fernanda Jansen Mira. A edição fotográfica como construção de uma narrativa visual. Discursos Fotográficos, Londrina, v. 3, n. 3, p.81-96, jan. 2007.

EID-SABBAGH, Yasmine. Extending Photography: the Meta-Medial/Conversational Layers of Dematerialized Photographs. Photography And Culture, Reino Unido, v. 12, n. 3, p.307-320, set. 2019.

FALANDES, Carolina Gois; ANGELUCI, Alan César Belo. A Imagem Digital em Perspectiva: Percepções sobre a Linguagem 360 no Cotidiano dos Jovens. In: GORDILLO, Inmaculada et al (org.). Perspectivas Imagéticas. Aveiro, Portugal: Ria Editorial, 2019. p. 207-234. Disponível em: http://www.riaeditorial.com/index.php/perpectivas-imageticas/. Acesso em: 30 mar. 2020.

HAND, Martin. Ubiquitous photography. Cambridge: Polity Press, 2012.

KLIMT, Andrea C. New ways of seeing: enhancing student learning through community-based collaborative photography. Visual Studies, v. 33, n. 2, p.127-143, ago. 2018.

LEVY, Yair; ELLIS, Timothy J. A system approach to conduct an effective literature

${ }_{3}$ Manoela de Souza, http://lattes.cnpq.br/3641092624017931 e manudesza@gmail.com. 
review in support of information systems research. Informing Science Journal, v.9, p.181-212, 2006. Disponível em: http://inform.nu/Articles/Vol9/V9p181-212Levy99. pdf. Acesso em: 22 jan. 2020.

LÓPEZ-DEL-RAMO, Joaquín B. Formatos novedosos del fotoperiodismo digital. Propuesta analítica basada en indicadores estructurales, formales y funcionales. Investigación Bibliotecológica, México, v. 31, n. 73, p.63-89, set. 2017.

MACHADO, Arlindo. A fotografia como expressão do conceito. Studium, Unicamp, 2000. Disponível em: http://www.studium.iar.unicamp.br/dois/1.htm. Acesso em: 28 dez. 2019.

MANOVICH, Lev. Instagram and Contemporary Image. [S.L.]: [s.n.], 2017. 148 p. Disponível em: http://manovich.net/content/04-projects/144-instagram-and-contemporary-image/instagram_book_manovich.pdf. Acesso em: 30 jan. 2020.

NIEBERDING, William J. Photography, phenomenology and sight: Toward an understanding of photography through the discourse of vision. 2011. Tese de Doutorado. The Ohio State University.

PALÁCIO, Maria Augusta Vasconcelos; CIANNELLA, Diana; STRUCHINER, Miriam. Narrativas Digitais e Aprendizagem: um panorama a partir do ensino da saúde. Reciis: Rev Eletron Comun Inf Inov Saúde, Rio de Janeiro, v. 2, n. 11, p. 1-15, jun. 2017. Disponível em: https://www.reciis.icict.fiocruz.br/index.php/reciis/article/view/1111. Acesso em: 08 abr. 2020.

PETTERSON, Rune. Using Images. Sweden: Institute for Infology, 2019.

RIVERA, C. D. Enseñanza de la fotografía en ambientes virtuales de aprendizaje. In: Undécima Conferencia Iberoamericana en Sistemas, Cibernética e Informática, Anais... 2012.

RODRIGUES, Walace. Letramento imagético e midiático em arte-educação. Conhecimento e Diversidade, Niterói, v. 6, n. 12, p.90-101, 2014. Disponível em: http:// www.revistas.unilasalle.edu.br/index.php/conhecimento_diversidade/article/ view/1607/1295. Acesso em: 08 jan. 2020.

RUBINSTEIN, Daniel. Towards Photographic Education. Photographies, [s.l.], v. 2, n. 2, p.135-142, 8 set. 2009. Disponível em: https://www.academia.edu/528410/ Towards_Photographic_Education. Acesso em: 10 jan. 2020.

SAMPAIO, R. F.; MANCINI, M. C. Estudos de revisão sistemática: um guia para síntese criteriosa da evidência científica. Revista Brasileira de Fisioterapia, 11, (1), 83-89, 2007. 
SANTAELLA, Lúcia. Linguagens líquidas na era da mobilidade. São Paulo: Paulus, 2014.

SCHWALBE, Michael. Framing the Self. Symbolic Interaction, v. 32, n. 3, p.177-183, set. 2009.

SOBRAL, João Eduardo Chagas. A linguagem fotográfica na formação do designer em um ambiente de convergência tecnológica. 2011. 145 f. Tese (Doutorado) - Curso de Pós-graduação em Design, Departamento de Artes e Design do Centro de Teologia e Ciências Humanas, Pontifícia Universidade Católica do Rio de Janeiro - Puc-rio, Rio de Janeiro, 2011. Disponível em: https://www.maxwell.vrac.puc-rio.br/ Busca_etds.php?strSecao=resultado\&nrSeq=21687@1. Acesso em: 24 jan. 2020.

TRANFIELD, D.; DENYER, D.; SMART, P. Towards a Methodology for Developing Evidence-Informed Management Knowledge by Means of Systematic Review. British Journal of Management, v. 14. p. 207-222, 2003. Disponível em: http://onlinelibrary.wiley.com/doi/10.1111/1467-8551.00375/epdf. Acesso em: 24 jan 2020.

WEBSTER, Jane; WATSON, Richard T. Analyzing the past to prepare for the future: Writing a literature review. MIS quarterly, v.26, n.2, pp.13-23, 2002. Disponível em: https://edisciplinas.usp.br/pluginfile.php/4031558/mod_resource/content/1/ ANALYZING\%20THE\%20PAST\%20TO\%20PREPARE\%20FOR\%20THE\%20FUTURE-\%20WRITING\%20A\%20LITERATUR.pdf. Acesso em: 22 jan. 2020.

Recebido em: 14/04/2020 Aceito em: 08/05/2020 